\title{
Automated library booktruck for traditional libraries
}

\author{
J. J. Spies ${ }^{1}$, B. Kotze ${ }^{2}$ \\ ${ }^{1}$ Department of Computer Systems Engineering, Tshwane University of Technology, South Africa \\ ${ }^{2}$ Department of Electrical, Electronic and Computer Engineering, Central University of Technology, South Africa
}

\begin{tabular}{|c|c|}
\hline Article Info & ABSTRACT \\
\hline Article history: & \multirow{9}{*}{$\begin{array}{l}\text { Libraries are an integral part of our society's knowledge repository and even } \\
\text { though technological advances such as the internet, smart devices and an } \\
\text { 'always-connected-society', provide avenues for fast and almost } \\
\text { instantaneous access to knowledge, libraries still provide a physical place for } \\
\text { the collection and dissemination of knowledge. The prompt shelving of the } \\
\text { physical returned library books is an important task in any traditional library. } \\
\text { To help speed up the shelving process, this paper proposed and simulated an } \\
\text { automated booktruck that is capable of moving returned library books from } \\
\text { the return desk back to the shelves. The simulation models currently } \\
\text { available robotic hardware and implemented path finding and localization. } \\
\text { The simulation results showed that returned books can be delivered to the } \\
\text { shelves four times faster than the by using the current practices. }\end{array}$} \\
\hline Received Sep 8, 2018 & \\
\hline Revised Feb 10, 2019 & \\
\hline Accepted Feb 25, 2019 & \\
\hline Keywords: & \\
\hline Autonomous vehicle & \\
\hline Library & \\
\hline Localization & \\
\hline Path-finding & \\
\hline
\end{tabular}

Copyright (C) 2019 Institute of Advanced Engineering and Science. All rights reserved.

Corresponding Author:

\section{J. J. Spies,}

Wireless and Radio Science Centre,

Department of Computer Systems Engineering,

Tshwane University of Technology,

South Africa

\section{INTRODUCTION}

The process of physically moving returned library books from the lending desk back to their respective shelves and physically shelving the books, is an important albeit tedious process in any library. In a traditional library, when a book is returned, it is scanned into the Library Information Systems (LIS) and placed on a booktruck or other staging area, to be shelved at the convenience of the library staff, or using the protocol implemented by the library.

Studies done by the University of Virginia and Bryan College have shown that library books take between 1 and 5 days to travel from the return desk to their relevant shelves. The study from the University of Virginia also showed that book pick-ups are done more frequently from the most obvious places, such as shelve ends, and less frequently from the less obvious places, such as study cubicles [1]. This delay shelving the books and picking up the books, leads to books showing as available in the library database but which are not available on the shelves, in turn leading to frustration amongst users since books cannot be found [2].

A study done by [3] on shelving concluded that shelving is a repetitive and physically demanding task, especially when trolleys full of books need to be moved from the circulation desk to the relevant shelves. This physically demanding task can be alleviated by implementing service robots [4].

The results of this study show that it is possible for a service robot to move books from the lending desk back to a collection spot in a short enough time to significantly reduce material dead time. By implementing an automated booktruck having this automated booktruck, library material dead time will be shorter and the physically demanding task of pushing a heavy booktruck is eliminated. 


\section{LITERATURE REVIEW}

Robotics in libraries are not something new. The first robot used in a library was in a Swedish library [5] at the lending desk. Books were placed on a conveyer system from where the robotic arm would identify each book and place it in a dedicated slot for later shelving. Since the introduction of robots and technology in libraries, research continues in the following areas.

\subsection{Inventory Control}

Inventory control and finding books when they are already shelved, using shelf scanning methods which incorporates radio frequency identification (RFID) tags, placed inside the books, and/or barcode numbers attached to the back of books [6-9].

\subsection{Book manupilation}

Placing books back into shelves or retrieving books from shelves is termed as book manupilation. Purpose built grippers attached to robotic arms [10, 11], and also teleoperation interfaces for retrieving books from shelves or storage locations, with the capability of opening and paging through the book while viewing the page content [12] is part of the current research.

\subsection{Library Asistants}

Hugh is the latest iteration of library assistant robots [13]. Hugh will be able to take verbal commands and then take the library user to where the specified book can be found. A framework for simplifying book finding in a children's library was developed by [14], while [15] developed a library assistant capable of assisting the elderly and other individuals to find library resources quicker.

\section{MOTIVATION FOR AUTOMATED BOOKTRUCK}

In contrast to the previous research, the authors of this paper have identified that no-one has looked at an automated way of moving books from the lending desk back to the shelves and therefore this paper proposes an automated booktruck which will identify books using embedded RFID tags and move books from the lending desk back to central collection points amongst the shelves. These collection points are then visited by shelvers from where the returned books are manually shelved into the correct position. No attempts will be made to shelve the books.

\section{SIMULATION OVERVIEW}

To test the hypothesis that an automated booktruck will reduce material dead time in traditional libraries, a simulation of an automated platform was performed using the library map of the Tshwane Univeristy of Technology's, Soshanguve South campus.

The simulator was written in Processing, a flexible software sketchbook and language for learning how to code within the context of the visual arts. Since Processing is intended to promote visual literacy, creating and working with screen objects and graphics, implementation of these objects is uncomplicated, simple and easily achieved.

The hardware platform used as basis for the simulated model, is the Robot Base Kit (\#28976, \#28977) and the motor mount and wheel kit (\#27971) with Position Controller (\#29319) all of which were available from Parallax Inc. It was selected because it closely resembles the footprint of an average human being. It is also big enough to carry books to the drop-off points.

Seven sonar sensors were used to achieve localization with their secondary purpose being obstacle avoidance. These sensors cover the front of the robot. Figure 1 shows the placement of the ultrasonic sensors. To reduce crosstalk, distance detection is done implementing the following sequence: 3, 0, 4, 1, 5, 2, 6. A Microsoft Kinect Sensors were used as primary obstacle detector. The data received is converted into 2dimensions which is then used to update the map of the environment. 


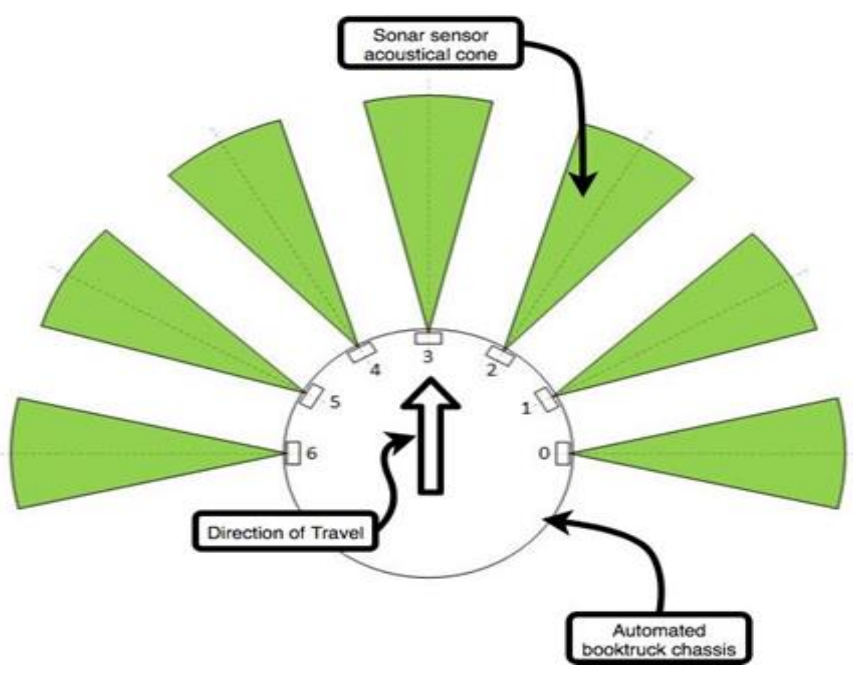

Figure 1. Ultrasonic Sensor Placement

\section{SIMULATOR}

Figure 2 shows a fictitious floorplan which highlights the conversion of the imported map into an occupancy grid. It also shows the node creation using the Quad-tree method, the robot position (green circle), the goal position (target sprite), the global route to follow (green line) the sonar sensor data used for localization (small white circles) and the best guess of the robot position using particle filters (red circles).

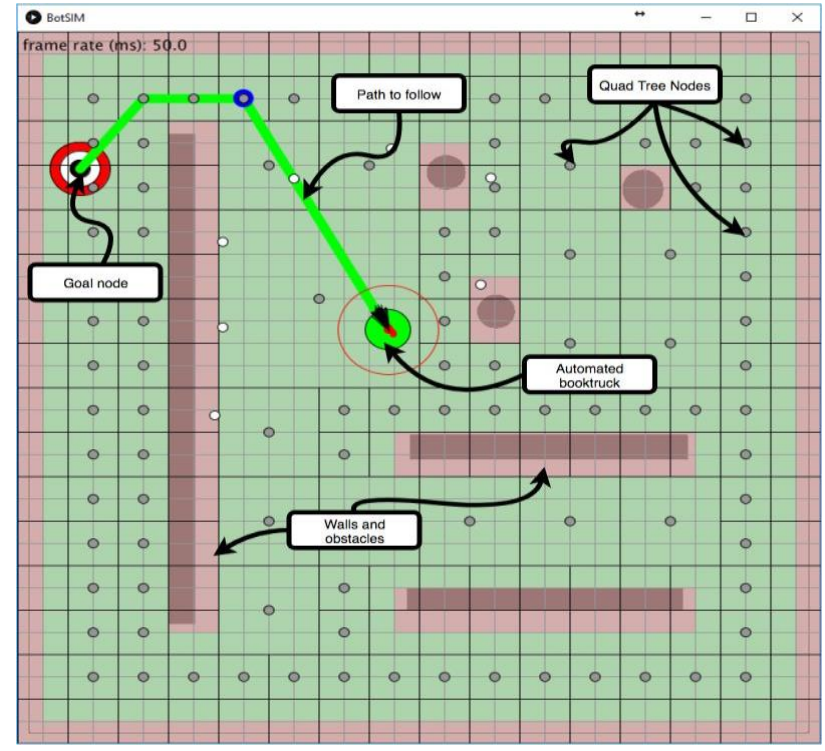

Figure 2. Example Floor Layout

\subsection{Environmental map}

The simulation was done using the floorplan and open collection area of the library at the Soshanguve South (SSoc) campus of the Tshwane University of Technology (TUT). Figure 3 shows the ground floor of the library while Figure 4 shows the floorplan, converted into an occupancy grid map during simulation.

This floorplan can be created by scanning a floor layout of the environment or by drawing the floor layout using CAD software or similarly suited software able to export a drawing as a JPG or PNG file. The dimensions of the exported picture are used to correctly determine the scale of the objects on the map and to place detected obstacles on the map. 
When the simulator starts it will import the map and divide the map into an occupancy grid equivalent map. The tiles in this occupancy grid keeps data like walls, obstacles, etc. which is used by the path planning phase to determine the best path to the selected drop-off point.

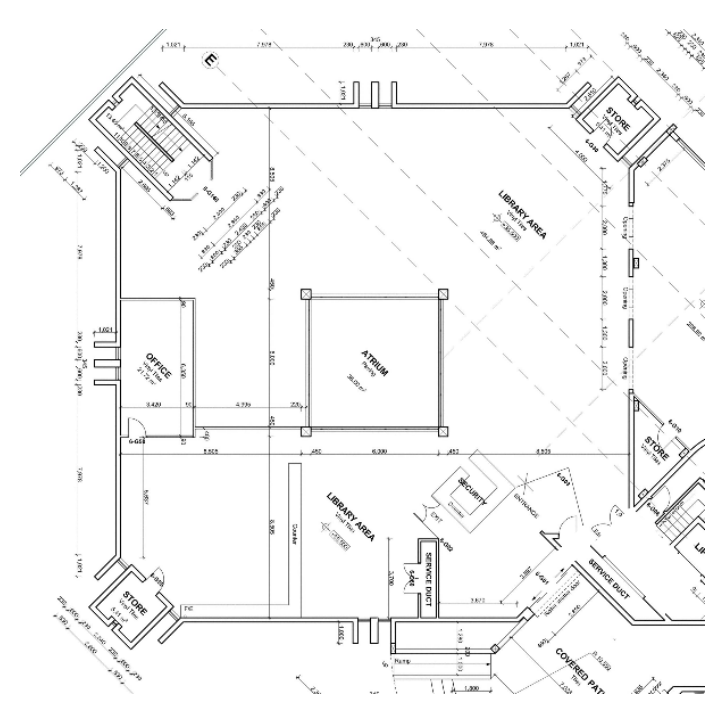

Figure 3. Library Floor Plan

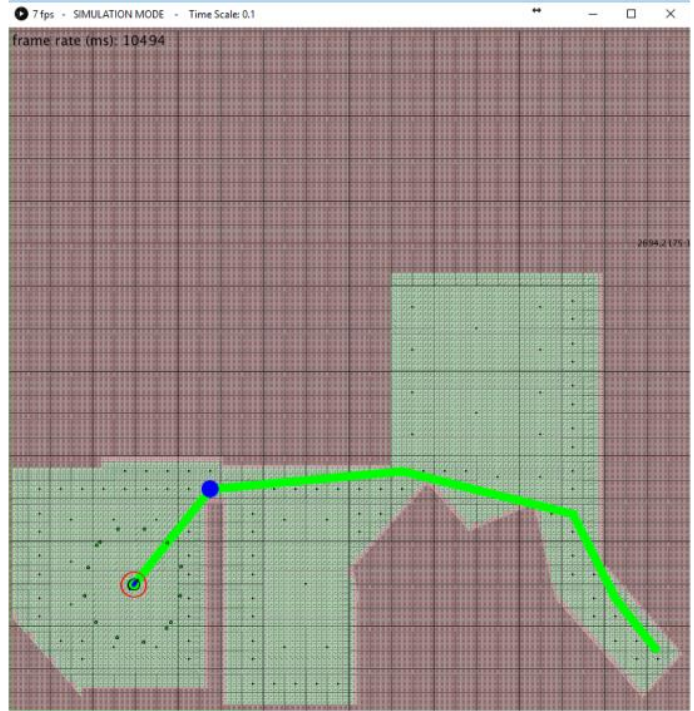

Figure 4. SSoc Ground Floor

\subsection{Path Planning}

Global path planning is achieved using the A-star path planning algorithm [16]. The path starts at a START node and ends at a GOAL node. The START node is the current booktruck position and the GOAL node the drop-off point for the book. The path is constantly being updated using data form the map.

\subsection{Local Path Planning}

Local navigation is achieved by using the potential field method where a pushing and pulling forces are combined to movement vectors. The pulling force is created by the next node in the path towards the goal position. Pushing forces are created away from all the obstacles. Two types of obstacles exist: 1) Fixed obstacles which is part of the initial map, for example: walls, book shelves and other fixtures on the floor of the environment, and 2) Random obstacles which are obstacles detected by the Kinect Sensor. A decay value is attached to random obstacles. This decay value removes the obstacles from the map after it expired to simulate the possible movement of random obstacles.

By combining the pushing and pulling forces, a vector, representing the speed and direction the robot should travel in, is created. Applying this vector to the robot has the robot reach the goal while avoiding any immediate obstacles. Any obstacles detected, while the booktruck moves, are added to the map. These new additions to the map influence the potential field, leading to new routes and movement patterns.

\subsection{Localization}

The purpose of localization is to estimate the robot pose using sensor data. When localized, the robot will be able to determine the optimized path between its current location and the next node position in the path towards the goal location. Localization is achieved by using simulated odometry and sonar data. Both data sets had noise values added to simulate real world conditions.

\section{RESULTS}

For this paper, an existing mobile platform was simulated using the floorplan of the SSoc at TUT to determine if it is possible for an automated booktruck to return books to the shelves in less time. The lending desk is on the ground floor while the open shelves are on the first floor. To overcome this problem, the simulation was divided into two parts. The first part simulated the robot moving towards the stairs on the ground floor, and the second part of the simulation measured time taken from the stairs' landing on the first floor to the relevant drop off point between the shelves. These two times were added together to produce a 
total time in one direction. This time was then multiplied by two to provide for the robot to return to the lending desk.

The data retrieved from the Library Information Systems (LIS) is graphically depicted in Figure 5. This graph shows the number of books returned per month for the year, 2016.

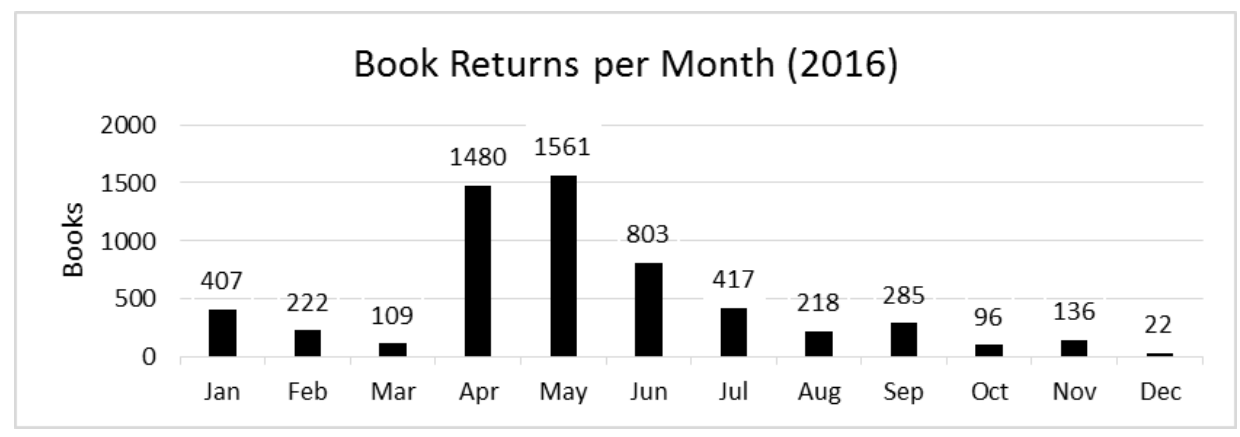

Figure 5. Book returns per month for the year 2016

This data set was then converted into a time value shown in Figure 6. This minute value represents the maximum time available to return a book to the shelve. This value was calculated using the monthly data from Figure 5 and assuming a total of 21.8 working days per month, with a typical workday consisting of 8 hours.

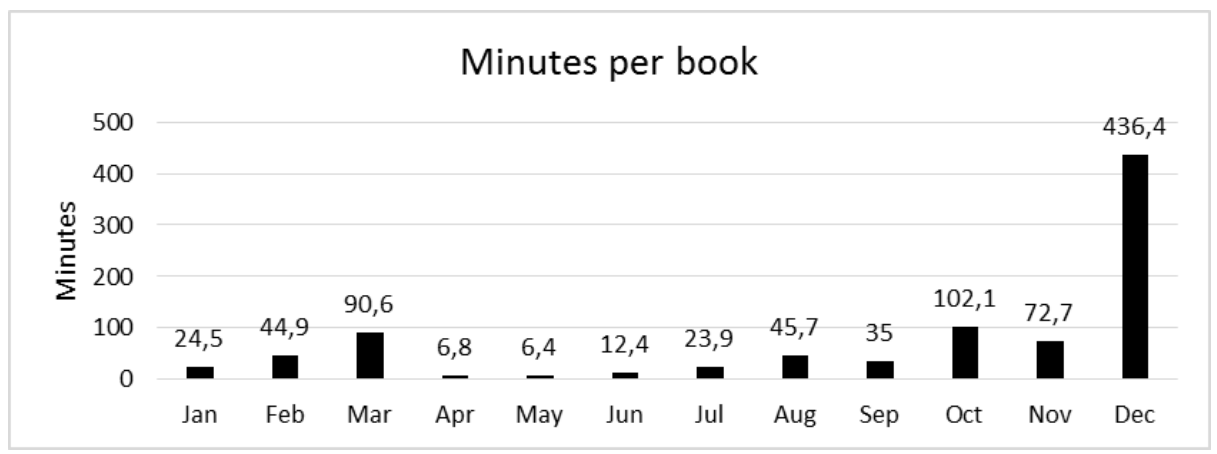

Figure 6. Time taken to shelve a single book

The maximum speed of the simulated booktruck was set at only $100 \mathrm{~cm} / \mathrm{s}$. The starting position of the robot randomly picked within a $1 \mathrm{~m}$ by $2 \mathrm{~m}$ area behind the lending desk, this simulates an inexact starting point after returning from the shelves. The simulation was done a total of ten times for each of the floors. These values, which consisted of distance and time, was then added to determine a total time and a total distance covered as shown in Table 1.

Table 1. Results of Simulated Data

\begin{tabular}{cccccc}
\hline \multicolumn{2}{c}{ Lending Desk to Stairs } & \multicolumn{2}{c}{ Stairs to drop off bin } & \multicolumn{2}{c}{ Total Return Data } \\
Distance $(\mathrm{cm})$ & Time $(\mathrm{s})$ & Distance $(\mathrm{cm})$ & Time $(\mathrm{s})$ & Distance $(\mathrm{cm})$ & Time $(\mathrm{s})$ \\
\hline 2546.433 & 25.7 & 1867.719 & 19 & 8828.304 & 89.4 \\
2544.989 & 25.6 & 1864.812 & 18.8 & 8819.602 & 88.8 \\
2479.516 & 24.9 & 1868.632 & 19.1 & 8696.296 & 88 \\
2464.285 & 24.8 & 1864.812 & 18.8 & 8658.194 & 87.2 \\
2487.262 & 25 & 1866.515 & 18.9 & 8707.554 & 87.8 \\
2424.416 & 24.4 & 1866.515 & 18.9 & 8581.862 & 86.6 \\
2493.986 & 25.1 & 1864.812 & 18.8 & 8717.596 & 87.8 \\
2415.776 & 24.4 & 1864.812 & 18.8 & 8561.176 & 86.4 \\
2487.811 & 25.1 & 1867.719 & 19 & 8711.06 & 88.2 \\
2534.231 & 25.5 & 1866.515 & 18.9 & 8801.492 & 88.8 \\
& \multicolumn{7}{c}{ Averages } & 8708.3136 & 87.9 \\
\hline
\end{tabular}


An average time of the total times was calculated and then compared to the values from Figure 6 to determine if the booktruck would be faster. In all the values calculated for each month, the booktruck time was less by at least a factor of 4 . The following conclusions were made when analyzing the data:

- Based on the total return time, an automated booktruck will be able to return books to the designated drop off points well within the calculated book return times as shown in the Figure 6.

- The SSoc is a small library and data might look different in large and busy libraries.

\section{FUTURE WORK}

Although Processing was used to create the simulator, it is meant to be an IDE for quick sketches and to test smaller concepts and ideas. Even though the Processing IDE is capable of working with multiple files, the lack of robust debugging tools is a problem when implementing large projects. In future, the design will be moved over to Robotic Operating Systems (ROS) which will be used to verify the found results.

The Microsoft Kinect sensor is a proven sensor when it comes to robotics and automated vehicle navigation, however newer sensors have become available and ideally it must be replaced by the Intel RealSense range of sensors or a LIDAR range sensor.

Research can be conducted regarding a method of handling multiple pieces of library material at the same time. This might be achieved by adding a mechanism capable of identifying and handling more than one item or by having a separate dispensing unit for when the autonomous booktruck returns from the shelves, for example an adapted conveyer belt system based on [5]. This system might then automatically load the next book onto the booktruck. Together with multiple books, an AI implementation of route optimization can be employed to optimize the delivery of multiple books.

Informal discussion with library staff, when conducting measurements to verify the floorplan, revealed a concern regarding automation robbing staff members of jobs. Automation used to make one's life easier was not seen as an issue if it assisted people and did not rob them of jobs.

\section{REFERENCES}

[1] M. Mitchell, "Library Workflow Redesign: Concepts and Results," Library Workflow Redesign: Six Case Studies, vol. 139, pp. 1, 2007.

[2] C. Cook and F. M. Heath, "Users' perceptions of library service quality: A LibQUAL+ qualitative study," Library Trends, vol. 49, pp. 548, 2001.

[3] F. N. Onifade, et al., "Staff Attitude to Shelving and Shelf Reading in Academic Libraries," North Carolina Libraries, vol. 68, pp. 12, 2010.

[4] H. Moradi, et al., "Service robotics (the rise and bloom of service robots)," Robotics \& Automation Magazine, vol. 20, pp. 22-24, 2013.

[5] R. Hansson, "Robot lends a hand in a Swedish library," Industrial Robot: An International Journal, vol. 22, pp. 3435, 1995.

[6] R. Li, et al., "AuRoSS: An Autonomous Robotic Shelf Scanning System,” in Intelligent Robots and Systems (IROS), 2015 IEEE/RSJ International Conference on, pp. 6100-6105, 2015.

[7] M. K. Sinha and A. Chanda, "Exploring RFID Technology Application for Managing Library and Information Services in University and Institutional Libraries of North East India: An Overview," Sinha, Manoj Kumar and Chanda, Anupam (2014). Exploring RFID Technology Application for Managing Library and Information Services in University and Institutional Libraries of North East India: An overview. International Journal of Information Sources and Services, vol. 1, 2014.

[8] M. Rashid, et al., "Sorting and Retrieval Robotic System Controlled via Programmable Logic Controller for Library Usage," International Journal of u-and e-Service, Science and Technology, vol. 7, pp. 19-30, 2014.

[9] J. Thirumurugan, et al., "Line following robot for library inventory management system," in Emerging Trends in Robotics and Communication Technologies (INTERACT), 2010 International Conference on, pp. 1-3, 2010.

[10] M. Prats, et al., "The UJI librarian robot," Intelligent Service Robotics, vol. 1, pp. 321-335, 2008.

[11] B. K. Kim, et al., "Design and control of the librarian robot system in the ubiquitous robot technology space," in RO-MAN 2008 - The 17th IEEE International Symposium on Robot and Human Interactive Communication, pp. 616-621, 2008.

[12] T. Tomizawa, et al., "Book browsing system using an autonomous mobile robot teleoperated via the internet," in Intelligent Robots and Systems, 2002. IEEE/RSJ International Conference on, vol. 2, pp. 1284-1289, 2002.

[13] "Robot librarian designed by Aberystwyth University students," $2016 . \quad$ Available: https://www.timeshighereducation.com/news/robot-librarian-designed-aberystwyth-university-students.

[14] W. Lin, et al., "Developing a service robot for a children's library: A design-based research approach," Journal of the Association for Information Science and Technology, vol. 65, pp. 290-301, 2014.

[15] J. Behan and D. T. O'Keeffe, "The development of an autonomous service robot. Implementation: 'Lucas'-The library assistant robot," Intelligent Service Robotics, vol. 1, pp. 73-89, 2008. 
[16] F. Duchon, et al., "Path planning with modified a star algorithm for a mobile robot," Procedia Engineering, vol. 96, pp. 59-69, 2014.

\section{BIOGRAPHIES OF AUTHORS}

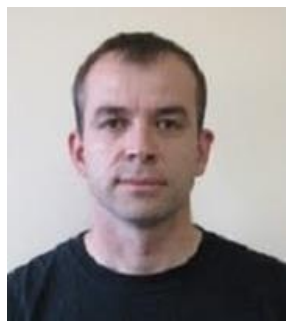

Jan Spies is lecturer at the Tshwane University of Technology in the Computer Systems Engineering Department, within the Faculty of Information and Communication Technolgy. His current research include system automation applications and practical AGV implementation.

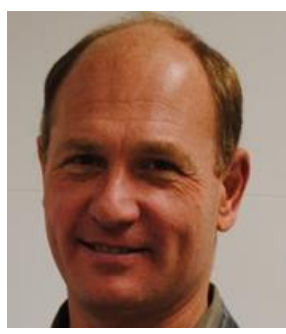

Ben Kotze is currently doing research on vision, several different AGV's, renewable energy systems, simulation and control, augmented reality systems and database prediction. He is a senior lecturer and researcher in the Department Electrical and Computer Systems Engineering at the Central University of Technology, Free State. Also an Activity Leader for the Automated Guided Vehicles group in the Research Unit for Evolvable and Manumation Systems (RGEMS). 